\title{
Deep currents in the Gulf of Guinea: along slope propagation of intraseasonal waves
}

\author{
C. Guiavarc' ${ }^{1,3}$, A. M. Treguier ${ }^{1}$, and A. Vangriesheim ${ }^{2}$ \\ ${ }^{1}$ Laboratoire de Physique des Oceans, IUEM, CNRS-IFREMER-IRD-UBO, BP 70, 29280 Plouzané, France \\ ${ }^{2}$ Laboratoire Environnement Profond, IFREMER, BP 70, 29280 Plouzané, France \\ ${ }^{3}$ Met Office, FitzRoy Road, Exeter, Devon, EX1 3PB, UK
}

Received: 28 October 2008 - Published in Ocean Sci. Discuss.: 7 January 2009

Revised: 3 April 2009 - Accepted: 11 May 2009 - Published: 18 May 2009

\begin{abstract}
In the Gulf of Guinea, intraseasonal variability is large at the equator and along the coast. Current data on the continental slope near $7.5^{\circ} \mathrm{S}$ show very energetic biweekly oscillations at $1300 \mathrm{~m}$ depth. A high resolution primitive equation numerical model demonstrates that this deep variability is forced by equatorial winds, through the generation of equatorial Yanai waves that propagate eastward and at depth, and then poleward as coastally-trapped waves upon reaching the coast of Africa. Intraseasonal variability is intensified along the coast of the Gulf of Guinea, especially in the 10-20 day period range and at depths between 500 and $1500 \mathrm{~m}$. The kinetic energy distribution is well explained at first order by linear theory. Along the equator, eastward intensification of energy and bottom intensification are in qualitative agreement with vertically propagating Yanai waves, although the signal is influenced by the details of the bathymetry. Along the coast, baroclinic modes 3 to 5 are important close to the equator, and the signal is dominated by lower vertical modes farther south. Additional current meter data on the continental slope near $3^{\circ} \mathrm{N}$ display an energy profile in the 10-20 day period band that is strikingly different from the one at $7.5^{\circ} \mathrm{S}$, with surface intensification rather than bottom intensification and a secondary maximum near $800 \mathrm{~m}$. The model reproduces these features and explains them: the surface intensification in the north is due to the regional wind forcing, and the north-south asymmetry of the deep signal is due to the presence of the zonal African coast near $5^{\circ} \mathrm{N}$. A 4 years time series of current measurements at $7.5^{\circ} \mathrm{S}$ shows that the biweekly oscillations are intermittent and vary from year to year. This intermittency is not well correlated with fluctuations of the equatorial winds and does not seem to be a simple linear response to the wind forcing.
\end{abstract}

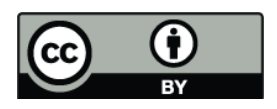

Correspondence to: A. M. Treguier (treguier@ifremer.fr)

\section{Introduction}

In the Gulf of Guinea, biweekly oscillations were first observed along the northern continental shelf by Houghton and Beer (1976) and Picaut and Verstraete (1979). These authors documented oscillations in time series of temperature and sea level at shallow depths, and assumed that these oscillations were nonlinearly forced by the tides (Houghton, 1979; Picaut and Verstraete, 1979). Variability that propagates along the coast, poleward along eastern boundaries, is generally interpreted in term of coastally-trapped waves or Kelvin waves. Clarke and Battisti (1983) discussed the observations in this context. They found that the baroclinic structure and propagation speed could match a standing mode of coastallytrapped waves, but in that case the oscillations would have a large amplitude at depth along the slope (for example, the mode 2 calculated by Clarke and Battisti (1983) had two maxima, one in the upper ocean and one at $2000 \mathrm{~m}$ depth). However, since there was no observation to confirm the presence of energy at such depths, Clarke and Battisti (1983) favored the interpretation of Picaut and Verstraete (1979): a generation by nonlinear interaction of tidal waves on the shelf in the vicinity of the Niger delta, and a vertical propagation limited to shallow depths.

The first direct observations of deep $(1300 \mathrm{~m})$ biweekly oscillations on the continental slope of the Gulf of Guinea have been reported recently by Vangriesheim et al. (2005), south of the equator at $7.5^{\circ} \mathrm{S}$, off the coast of Angola (Fig. 1). The measurements were carried out as part of the pluridisciplinary "Biozaire" program over a four-year period (20002004). The oscillations were bottom-intensified and oriented along the bathymetry with a peak-to-peak amplitude of more than $20 \mathrm{~cm} \mathrm{~s}^{-1}$. They completely dominated the sub-inertial variability at $30 \mathrm{~m}$ above the bottom. Comparison of the current meter data with the characteristics of coastally-trapped standing modes suggested that a combination of modes was necessary to explain the observed signal, with contributions

Published by Copernicus Publications on behalf of the European Geosciences Union. 


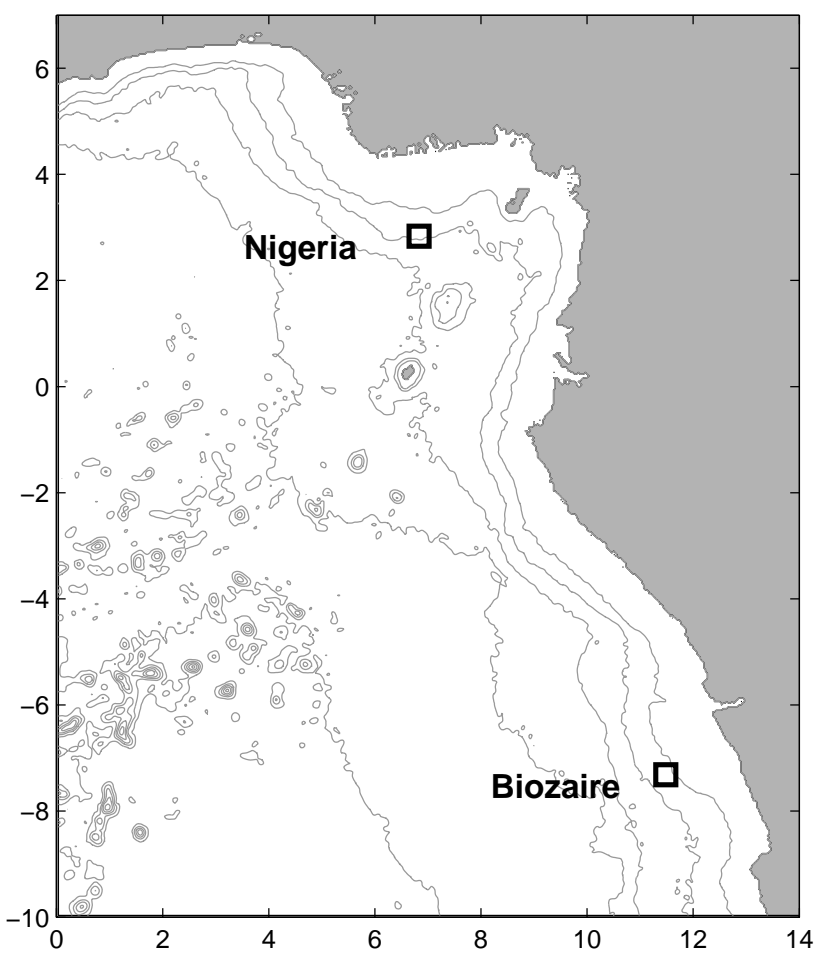

Fig. 1. Bathymetry of the Gulf of Guinea (isobaths 1000, 2000, 3000,4000 and $5000 \mathrm{~m}$ ) and position of the mooring sites Biozaire and Nigeria.

from modes 3 and 5. Vangriesheim et al. (2005) pointed out that the complex baroclinic structure, the large velocities at $1300 \mathrm{~m}$ and the variability of the signal from year to year made it unlikely that this biweekly energy could be generated by tides alone.

In order to investigate the origin of the variability found on the Biozaire site, Guiavarc'h et al. (2008) have constructed a regional three-dimensional numerical model (the "GUINEA" model). The GUINEA model does not include tides, but nevertheless it reproduces well the 14-day oscillations observed at the location of the current meter measurements, in terms of amplitude, along-slope orientation and bottom intensification. Guiavarc'h et al. (2008) conclude that the biweekly oscillations could well be entirely forced by the wind, and more precisely, the equatorial wind (between $5^{\circ} \mathrm{S}$ and $5^{\circ} \mathrm{N}$ ). Indeed, the same model forced by local winds near $7.5^{\circ} \mathrm{S}$ completely fails to reproduce the observed signal, which demonstrates that the variability at the Biozaire site is remotely forced. In the model, biweekly current oscillations with the properties of Yanai waves are found along the equator at depths between 500 and $1500 \mathrm{~m}$; time-latitude plots show the propagation of these oscillations poleward away from the equator. Typical phase speeds along the continental slope are 0.5 to $1.5 \mathrm{~m} \mathrm{~s}^{-1}$ depending upon location (Guiavarc'h et al., 2008).
This scenario of equatorial generation and coastal propagation of biweekly variability in the Gulf of Guinea is supported by recent observations and models in the three equatorial oceans. Variability at similar periods has been observed along the equator in the Pacific ocean (Zhu et al., 1998), in the Indian ocean (Sengupta et al., 2004; Miyama et al., 2006) and in the Atlantic ocean (Bunge et al., 2006, 2007; Han et al., 2008). These recent studies based on direct current measurements show that biweekly oscillations are especially large in the eastern equatorial Atlantic and in the Indian ocean, and they are present even at depth. Their propagation, structure and symmetry properties fit those of equatorial Yanai waves, and modelling studies confirm that they are mainly forced by equatorial winds (e.g., Miyama et al., 2006; Han et al., 2008). Moreover, eastward propagation of intraseasonal variability along the equator as Yanai and Kelvin waves and subsequent poleward propagation as coastallytrapped waves or coastal Kelvin waves has been observed and modelled extensively in the eastern Pacific ocean (see for example Enfield et al., 1987; Shaffer et al., 1997) and more recently in the Atlantic ocean as well (Polo et al., 2008). In the Gulf of Guinea, there are few in situ measurements along the coast, and the satellite data used by Polo et al. (2008) do not sample periods shorter than 20 days; however if the signal at longer periods propagates along the coast it should propagate even more so for the biweekly frequency. Indeed, all the biweekly energy reaching the eastern boundary at the equator must propagate poleward as coastally-trapped waves, due to the absence of westward propagating inertia gravity waves and Rossby waves in the 11-day to 30-day period band (Guiavarc'h et al., 2008).

It appears thus likely that intraseasonal variability of currents, and especially biweekly oscillations, can propagate away from the equator all along the coast of the Gulf of Guinea, even in the deep ocean. The main purpose of the present paper is to examine the characteristics of this intraseasonal variability along the continental slope, using the high resolution model GUINEA of Guiavarc'h et al. (2008). This model, with grid size of $1 / 12^{\circ}$ and 100 levels in the vertical, has been fully validated at the Biozaire site and its intraseasonal variability at the equator is in agreement with the observations of Bunge et al. (2006). It allows us to assess the relative importance of variability along the coast compared with the interior, not only at the biweekly frequency but over the full intraseasonal spectrum (periods between 2 and 90 days), at different depths. Since the basic dynamics are linear (free equatorial and coastally-trapped waves) we also develop a linear shallow water model to assess how much of the three-dimensional structure of the variability can be explained by linear theory.

The coastal geometry of the Gulf of Guinea is expected to alter the propagation of equatorial waves (for example, Philander, 1977; Kaufman et al., 1999). In the GUINEA model we find a asymmetry between the intraseasonal variability of deep currents north and south of the equator, but 
this result must be validated by measurements. For this purpose we present here new current meter data at $3^{\circ} \mathrm{N}$ along the continental slope, provided by TOTAL. The data cover the whole water column over a one-year period (May 2001 to May 2002). It confirms the presence of biweekly current oscillations down to the bottom (1360 m depth) north of the equator, but the vertical profile of kinetic energy is strikingly different from the Biozaire site. The GUINEA model is in very good agreement with these new data, and will help us to explain the North-South asymmetry (together with sensitivity experiments carried out with the linear model).

Finally, Guiavarc'h et al. (2008) noted a strong interannual variability of the 14-day oscillations in the Biozaire data. Here we use the four years of data to document this intermittency using a wavelet analysis, and compare it with both the GUINEA and the linear model. Because of the similarity between the linear and nonlinear solution, it would be tempting to expect a simple relationship between the wind forcing at the equator and the intermittency on the Guinea site. This issue is investigated in the last section of this paper.

\section{Horizontal structure of the intraseasonal signal}

The regional model GUINEA is described in detail in Guiavarc'h et al. (2008), as well as in Appendix A. It is based upon the NEMO primitive equation code (Madec, 2008). The domain covers the Gulf of Guinea from $15^{\circ} \mathrm{S}$ to the Northern African coast and from $2.5^{\circ} \mathrm{W}$ to the eastern African coast (Fig. 2). It has 100 vertical levels and a $1 / 12^{\circ}$ horizontal grid. The model is spun up during years 19951999, and then forced by atmospheric data, including daily Quikscat winds, for years 2000-2004. The forcing at the south and west open boundaries is provided by daily output from a lower resolution model (see Appendix A). A general validation of the model is found in Guiavarc'h et al. (2008).

In the present paper we try to understand to what extent the structure of the intraseasonal variability can be explained by linear theory. To that purpose we have developed a linear model at $1 / 4^{\circ}$ resolution, where the solution is calculated independently for the first six baroclinic modes using the shallow water equations. The linear model is forced by daily Quikscat winds like the GUINEA model; it is described in Appendix B.

The variability of the upper layers has been examined using models and satellite data, for example by Han et al. (2008) or Polo et al. (2008). We focus on the intraseasonal variability of deep ocean currents (below $200 \mathrm{~m}$ depth) for which models are the main source of information at the regional scale. Frequency spectra of kinetic energy from the GUINEA model have been shown by Guiavarc'h et al. (2008) at the equator and at the Biozaire site. In order to analyze the three-dimensional structure of the variability, we have calculated kinetic energy spectra at many grid points over a 4-year period (2000-2003). Since we cannot show the spectra at
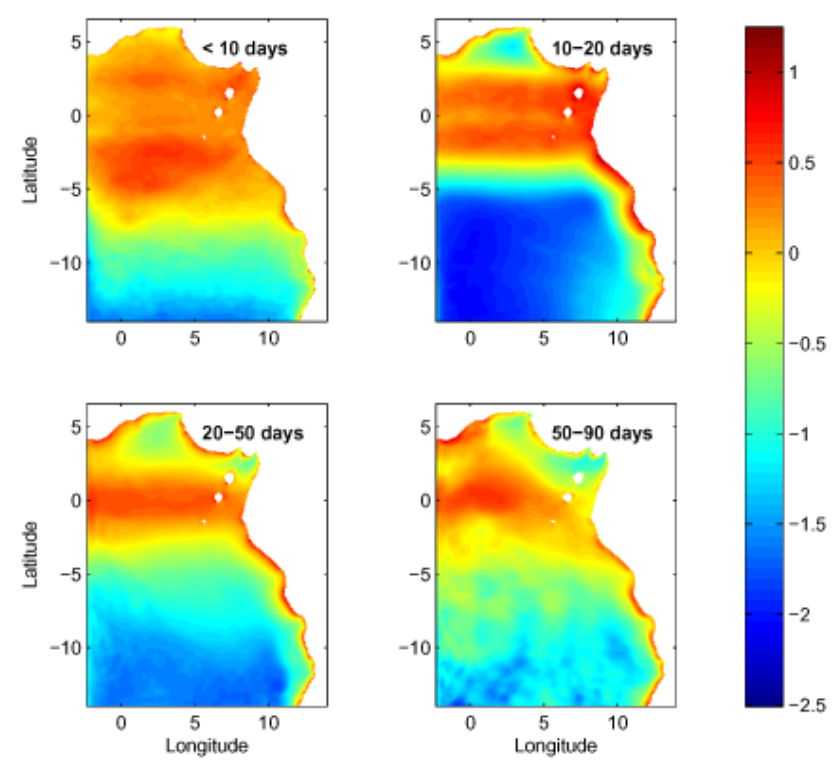

Fig. 2. $\log 10$ of the kinetic energy $\left(\mathrm{m}^{2} \mathrm{~s}^{-2}\right)$ at $1150 \mathrm{~m}$ depth in the GUINEA model for the 4 intraseasonal period bands: $2-10$ days, 10-20 days, 20-50 days and 50-90 days.

all locations we split the intraseasonal signal into four period bands for mapping purposes. The first band (periods between 2 and 10 days), includes inertial oscillations. The second band, 10-20 days, corresponds to the energetic biweekly signal described in Vangriesheim et al. (2005) and Guiavarc'h et al. (2008). The third band, 20 to 50 days, includes the periods of the tropical instability waves, and the fourth band spans the longer intraseasonal periods from 50 to 90 days. Spectra have been calculated at different depths. The biweekly current oscillations were observed at the Biozaire site near $1300 \mathrm{~m}$ depth; in the model the biweekly energy is intensified both at the equator and along the coast in the $500-1500 \mathrm{~m}$ depth range. We thus choose to present maps at $1150 \mathrm{~m}$ depth (Fig. 2); note that the logarithm of kinetic energy is displayed in order to better reveal the spatial structure.

As expected, the intraseasonal kinetic energy is intensified in the equatorial band. The meridional scale of enhanced equatorial energy decreases with increasing period. From periods shorter than 10 days to periods of 10-20 days, the decrease seems to be related to the critical latitude of inertiagravity waves (the critical latitude is $6^{\circ}$ for the 5 -day period and $3^{\circ}$ for the 10 -days period). Figure 2 reveals that the energy is also intensified along the coast outside the equatorial band. The coastally-trapped signal is very energetic all the way to the southern boundary of the domain at $15^{\circ} \mathrm{S}$. Note the logarithmic scale: at the latitude of Biozaire $\left(7.5^{\circ} \mathrm{S}\right)$ in the 10-20 days period band, the coastally-trapped energy is larger than the interior energy by 3 orders of magnitude. For both the equatorial signal and the coastally-trapped signal at 

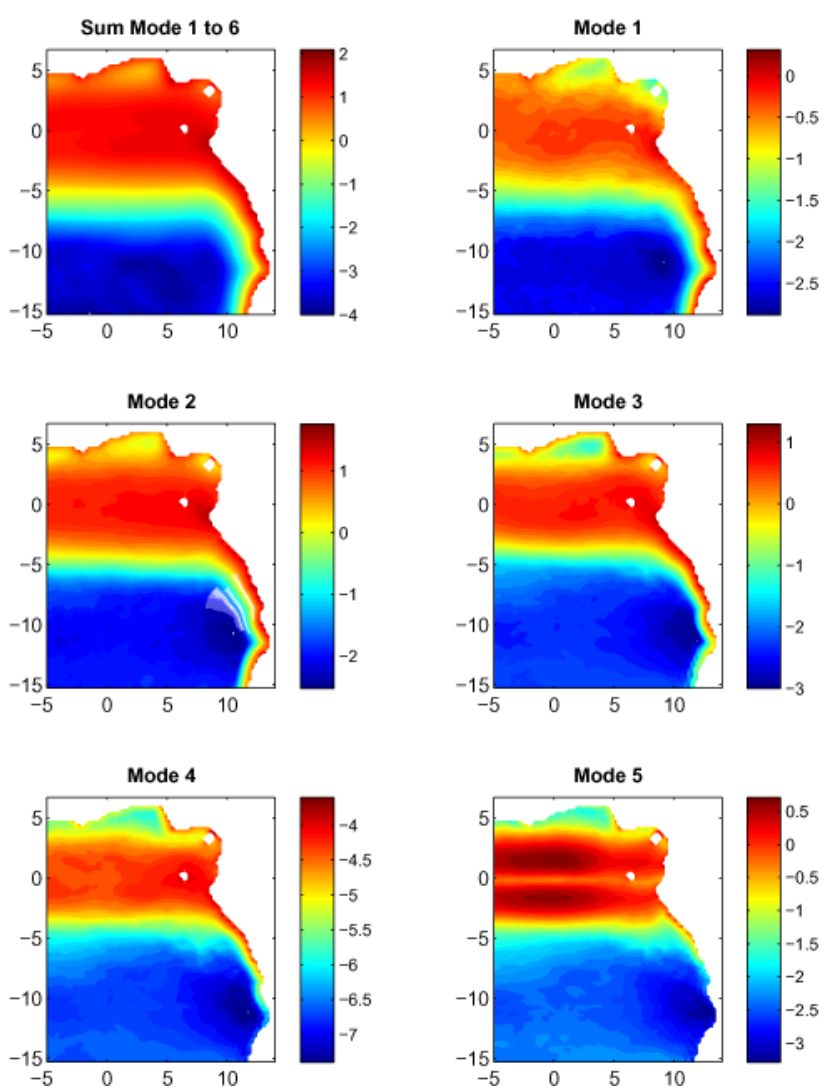

Fig. 3. $\log 10$ of the kinetic energy $\left(\mathrm{m}^{2} \mathrm{~s}^{-2}\right)$ in the 10-20 day period band at $1150 \mathrm{~m}$ in the linear model (horizontal maps, axis are longitude and latitude in degrees). The total response as well as the separate contribution of the first 5 baroclinic modes is indicated. The color scale is ajusted for each mode because different modes have very different amplitudes at a given depth. Note that the contrast between low energy regions and high energy regions is larger in the linear model than in the nonlinear model (compare Fig. 3a with Fig. 2).

$1150 \mathrm{~m}$, the 10-20 days period band is the most energetic. As demonstrated by Guiavarc'h et al. (2008), the energy peak along the coast comes from the fact that in the 10-20 days period band, there is no equatorial wave with westward group velocity. Therefore, the energy propagating toward the eastern boundary cannot be reflected and is totally converted into coastally-trapped waves. On the other hand, for shorter periods, inertial gravity waves can propagate energy in both directions, and for longer periods the energy can be partially reflected as Rossby waves. Even though they do not dominate the coastally-trapped signal, the longer periods are present along the coast. This result is in agreement with Polo et al. (2008) who have found that coastal Kelvin waves at a period of 2 months can propagate poleward to $12^{\circ} \mathrm{S}$ along the coast of the Gulf of Guinea, using satellite data and a $1 / 2^{\circ}$ numerical model. Our model suggests that this signal also exists at depth, and may propagate farther than $12^{\circ} \mathrm{S}$.
Note that Fig. 2 shows a clear difference between the propagation north and south of the equator, with more coastallytrapped energy along the southern coast: this will be discussed in more detail in Sect. 4. Maps similar to Fig. 2 at $500 \mathrm{~m}, 1500 \mathrm{~m}$ and $2000 \mathrm{~m}$ depth display similar characteristics (not shown). The high frequency signal is energetic at all the depths between $7^{\circ} \mathrm{S}$ and $5^{\circ} \mathrm{N}$, although it decreases with depth. It dominates over the other periods in the two extraequatorial bands $\left(7^{\circ} \mathrm{S}-2^{\circ} \mathrm{S}\right.$ and $\left.2^{\circ} \mathrm{N}-5^{\circ} \mathrm{N}\right)$ at all depths. For the equatorial $\left(2^{\circ} \mathrm{S}-2^{\circ} \mathrm{N}\right)$ and coastally-trapped energy, the dominant period changes with depths; for example the 20 50 days period band is the most energetic at $2000 \mathrm{~m}$.

To see if linear theory can explain the map of Fig. 2, we have plotted the same map for the 10-20 days periods using the results of the linear model (Fig. 3, top left panel). The kinetic energy is calculated by summing six vertical modes at the same depth $(1150 \mathrm{~m})$; note that this depth does not necessarily provide the best agreement between the two models, since the linear model has no bottom topography and an arbitrary total depth of $4000 \mathrm{~m}$. We find that the spatial structure of kinetic energy is quite similar in the GUINEA and the linear model, although the equatorial and coastal intensification is larger in the linear model (notice the difference in colorscale between Fig. 2 and 3) and the energy minimum near $4^{\circ} \mathrm{E}, 4^{\circ} \mathrm{N}$ is less marked. At the Biozaire site, Vangriesheim et al. (2005) interpreted deep biweekly oscillations as coastally-trapped waves, and they used the linear model of coastally-trapped waves developped by Brink and Chapman (1987) to show that the biweekly oscillations could be compatible with baroclinic modes 3 and 5 . In the Gulf of Guinea stratification is large, so that the coastallytrapped waves have characteristics close to coastal Kelvin waves (see dispersion diagram in Vangriesheim et al., 2005); in that regime coastally-trapped waves are at first order similar to coastal Kelvin waves following a slanted coast (Huthnance, 1978). This explains the skill of the flat bottom linear model in Fig. 3 to represent the intraseasonal waves both at the equator and along the coast.

The kinetic energy is also plotted for the first 5 baroclinic modes separately in Fig. 3. Each panel represents the contribution to the sum at $1150 \mathrm{~m}$, hence the small contribution for mode 4 which has a zero near that depth (Guiavarc'h, 2007). The equatorial trapping of the energy increases with the mode number, although less than one would expect for a single meridional mode based on the equatorial radius of deformation (which varies from $321 \mathrm{~km}$ for mode 1 to $153 \mathrm{~km}$ for mode 5). Between $8^{\circ} \mathrm{S}$ and $8^{\circ} \mathrm{N}$ the structure of the nonlinear solution (Fig. 2) resembles the third baroclinic mode, while at southern latitudes the variability along the coast is mostly explained by modes 1 and 2 . The energy propagates farther to the south for low order modes, because they have a longer decay time (Appendix B) and also because their larger horizontal scale is better resolved by the model grid, so that they are less subject to dissipation by the biharmonic viscosity. 
Let us consider the evolution of the coastal signal between the equator and $15^{\circ} \mathrm{S}$ in Figs. 2 and 3. The width of the coastal signal decreases to the south because the trapping scale of the signal decreases with latitude. This is true for all depths between $500 \mathrm{~m}$ and $1500 \mathrm{~m}$ (not shown). Clarke (1983) studied the reflection of equatorial waves on an eastern boundary. He demonstrated that for the case of meridional boundaries, since the trapping scale gets narrower as latitude increases, the amplitude of coastal waves increases proportionally to the square root of latitude in order to conserve energy. We find such an increase in amplitude from the equator to about $6^{\circ} \mathrm{S}$ especially for the 10-20 day and 2050 day period bands (not shown) but south of $7^{\circ} \mathrm{S}$ the amplitude of the signal decreases despite the narrower coastal trapping. A similar decay is found in the linear model where it is due to viscous processes. Using a shallow water model, Soares et al. (1999) found that a realistic shape of the coastline was more important than nonlinear effects for an accurate representation of the poleward energy flux at intraseasonal frequencies. In our fully three dimensional model (Fig. 2) the decrease of the intraseasonal energy is not monotonic following the coast. Rather, we observe local increases due to the coastline geometry especially between $4^{\circ} \mathrm{S}$ and $10^{\circ} \mathrm{S}$. Near $5^{\circ} \mathrm{S}$, the coastline forms a bay and the signal is weak whereas between $6^{\circ} \mathrm{S}$ and $8^{\circ} \mathrm{S}$ where the coastline forms a cape the signal increases (the Biozaire site is located in this region). In his study, Clarke (1983) showed that the curvature of the coastline changes the phase speed of the coastal kelvin waves: the waves slow down at capes and speed up in bays. We find that the effect of the coastline geometry is much larger in the nonlinear 3-D model than in the linear shallow-water case; it may be due to the fact that the continental slope is represented by a vertical wall in the linear model, whereas the slope width can vary as well as its orientation in the nonlinear model.

Time-latitude diagrams of the meridional velocity along the coast have been computed for both GUINEA and the linear model. An example is shown in Fig. 4 for the 10-20 day band-passed filtered velocities at $1000 \mathrm{~m}$ depth, for the year 2003. For both models, the apparent phase velocity (measured by the slope of the velocity patterns in the latitude/time plane) varies as the waves propagate southward. In the linear model, the phase velocity between the Equator and $5^{\circ} \mathrm{S}$ is approximatively $0.68 \mathrm{~m} \mathrm{~s}^{-1}$, i.e. between the phase velocities of modes 4 and 5 ( 0.71 and $0.54 \mathrm{~m} \mathrm{~s}^{-1}$, respectively), in agreement with the importance of higher baroclinic modes in the equatorial band. Between $5^{\circ} \mathrm{S}$ and $10^{\circ} \mathrm{S}$, the phase velocity of the 10-20 day signal in the linear model is approximatively $1.15 \mathrm{~m} \mathrm{~s}^{-1}$, closer to modes 2 and 3 , which is consistent with the decay of high-order modes apparent in Fig. 3. The poleward increase of the phase velocity is similar in the GUINEA and linear models, reflecting the changes in vertical structure. Between the Equator and $5^{\circ} \mathrm{S}$, the phase velocity of the 10-20 day signal is around $0.45 \mathrm{~m} \mathrm{~s}^{-1}$, i.e. close to the 6th-mode phase velocity. Between $5^{\circ} \mathrm{S}$ and $10^{\circ} \mathrm{S}$, it

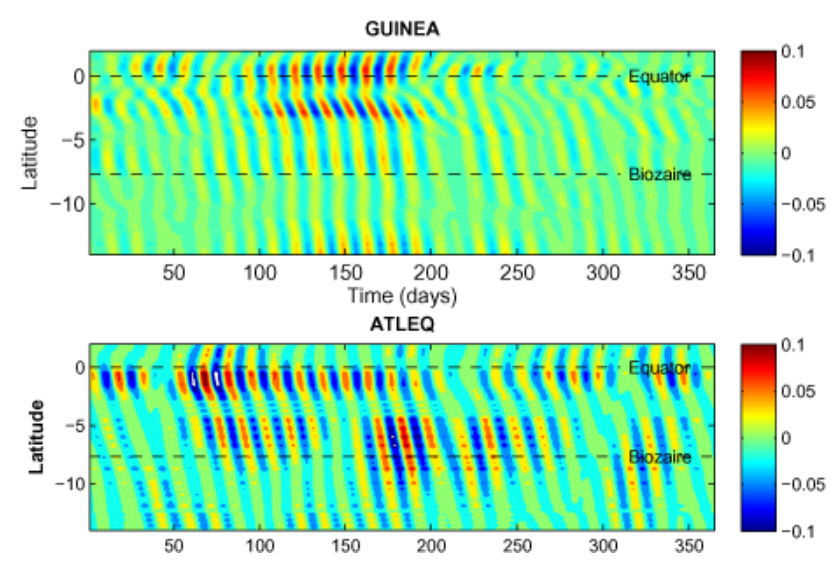

Fig. 4. Time-latitude plot of the 10-20 day filtered meridional velocity $\left(\mathrm{m} \mathrm{s}^{-1}\right)$ along the isobath $1000 \mathrm{~m}$ in the REF experiment of the GUINEA model (top) and in the linear model (bottom), for year 2003.

is more difficult to point out a particular velocity because the apparent phase velocity varies in time, from $0.63 \mathrm{~m} \mathrm{~s}^{-1}$ (between modes 4 and 5) to $1.54 \mathrm{~m} \mathrm{~s}^{-1}$ (close to mode 2). The apparent phase velocity tends to be larger when the amplitude of the oscillations is large. Phase velocities at a given depth cannot be explained in term of a single baroclinic mode, even in the linear model: for a single mode the slope of the velocity patterns in Fig. 4 would be completely independent of latitude, north and south of the equator.

\section{Vertical structure and vertical propagation}

In order to study the vertical structure of the intraseasonal energy, we have plotted sections at the equator, $4^{\circ} \mathrm{S}$ and $8^{\circ} \mathrm{S}$ for the four period bands (Fig. 5). Guiavarc'h et al. (2008) show separately a section of biweekly energy along the equator for the zonal and meridional velocity in their Fig. 10, demonstrating that the meridional velocity is dominant. Let us consider the change in vertical structure following the poleward propagation from the equator to $8^{\circ} \mathrm{S}$ (left to right). At all frequency bands, the energy decreases poleward, and the decrease is much larger at depth than near the surface, so that the vertical scale of the intraseasonal signal increases. For example, considering the 10-20 day period, at the equator the signal is present at depth around $1000 \mathrm{~m}$ and displays at least four maxima in the vertical. At $4^{\circ} \mathrm{S}$, the $1000 \mathrm{~m}$ depth signal is still present but the vertical scale is greater with 3 maxima only, and at $8^{\circ} \mathrm{S}$ the deeper maxima become relatively weaker. This evolution agrees with the linear solution, where a similar evolution of vertical scales occurs (not shown) due to the enhanced dissipation of higher baroclinic modes as they propagate poleward (this is apparent in Fig. 3). We have also plotted maps of the coastally-trapped energy as a function of depth and latitude (not shown): those maps 

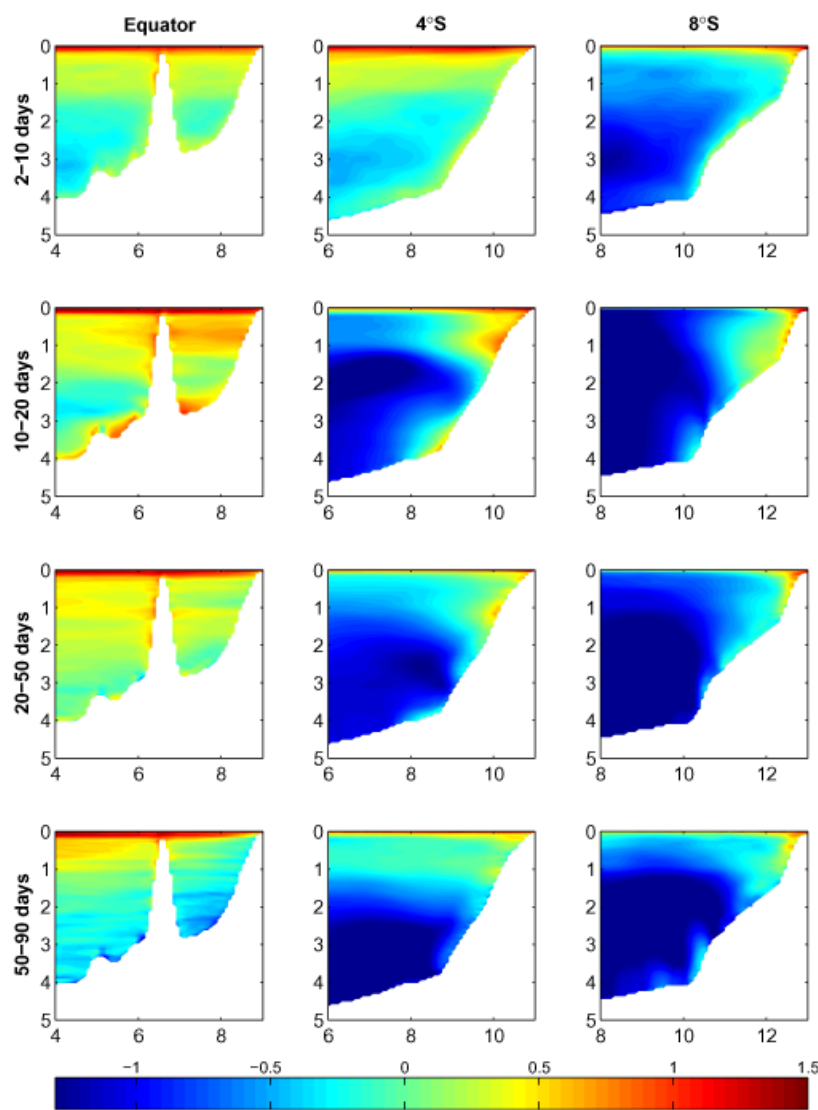

Fig. 5. Vertical sections of kinetic energy $(\log 10)$ in the GUINEA model at the Equator (left), $4^{\circ} \mathrm{S}$ (middle) and $8^{\circ} \mathrm{S}$ (right). The horizontal axis is longitude (in degree) and the vertical axis is depth (in $\mathrm{km})$. The sections have been drawn for the 4 period bands detailed on Fig. 2.

confirm that the vertical structure changes going poleward, but no clear vertical propagation appears, so that the formulation in terms of vertical modes seem the most adequate to describe the signal.

Let us now consider how the vertical structure varies with the period in Fig. 5. The vertical structure is most complex at the equator, where the longer periods seem to be associated with smaller vertical scales (higher baroclinic modes). This is consistent with the results of Hua et al. (2008), who demonstrates that vertical scale selection occurs with the following relationship between the period and the vertical mode: $p \approx 0.55 k^{2}$ with $p$ the period in days and $k$ the vertical mode. So we should observe a vertical mode 3 for the 5 -days period, a vertical mode 4 for the 10-days-period, a vertical mode 6 for the 20-days period, a vertical mode 9 for the 50-days period and a vertical mode 25 for the 1 -year period. However, when we project the model kinetic energy for the different periods on the linear baroclinic modes at different locations, no evident vertical mode emerges, perhaps due to the complexity of the bathymetry. Indeed the topography
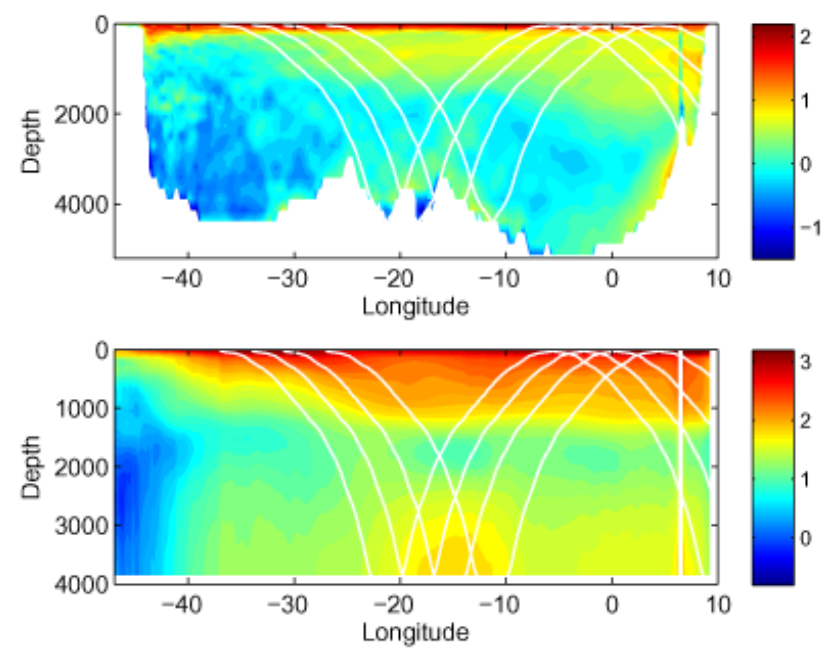

Fig. 6. Logarithm of the meridional component of the kinetic energy in the 10-20 days period at the Equator. NATL model (top), linear model (bottom). The white lines represent three equatorial beams for 14-day Yanai waves.

modifies the structure of the signal (especially near the Sao Tome Island at $7^{\circ} \mathrm{E}$ in Fig. 5 and for the 10-20 days periods).

In a model study of the deep seasonal variability along the equator, Thierry et al. (2006) found that a description in terms of vertically propagating waves rather than baroclinic modes could be more pertinent. Such a formalism applied to Yanai waves has been used to explain the structure of biweekly energy in the equatorial Indian ocean by Miyama et al. (2006). We follow the same approach to see if it could explain the vertical structure of the energy in the 10-20 day period (Fig. 5) and especially the deep energy maxima. We focus on the 10-20 day signal because for the other periods the description is more complex owing to the existence of westward propagating waves. We need to calculate energy ray paths originating west of the Gulf of Guinea, which is not possible in the GUINEA model because of its limited coverage. We thus use the $1 / 4^{\circ}$ Atlantic model NATL that has been integrated to provide the boundary conditions of the GUINEA model, and which has the same horizontal resolution as our linear model. An equatorial section of the logarithm of kinetic energy in the 10-20 day period band is presented in Fig. 6 for NATL and the linear model. The energy level at depth is higher in the linear model (note the difference in color scales). Regarding the structure, there are some similarities between the two models: the energy increases eastward, which is expected since all the equatorial waves in that period band (Kelvin and Yanai waves) propagate their energy eastward. At the eastern boundary, the linear model shows high energy from the surface to $1000 \mathrm{~m}$ and another maximum at the bottom; in the nonlinear model the energy has a well-defined maximum near $1000 \mathrm{~m}$. Some rays path for 14-day Yanai waves are indicated on Fig. 6. There is 
biweekly energy in the Quikscat winds all along the equator to force Yanai waves, so we cannot identify one preferred ray path: a few rays are plotted from arbitrary initial points to illustrate their shape. Below a ray path originating at the western boundary no energy propagates downward: there is thus a shadow zone without biweekly energy near the western boundary, visible in both linear and nonlinear models. In both cases two maxima are present in the deep layer near the bottom between $20^{\circ} \mathrm{W}$ and $10^{\circ} \mathrm{W}$ and between $0^{\circ} \mathrm{W}$ and the African coast. Those maxima can probably be interpreted as a bottom reflection of the rays, although the realistic shape of the topography makes the nonlinear model more complex. We note that the vertical structure of energy at $10^{\circ} \mathrm{W}$ in both models show the presence of biweekly energy near $800 \mathrm{~m}$, in agreement with the observations of Bunge et al. (2006).

In summary, the representation of the intraseasonal oscillations as propagative waves helps us to understand the structure of the signal along the equator (for example, why the upper layer of high energy deepens from the west of the basin to the east). However, the coastally-trapped waves along the boundary do not show any clear vertical propagation. The changes in the vertical structure along the coast away from the equator are explained to some extent by a decomposition in vertical modes; however details such as the energy intensification around topographic features cannot be represented by a linear model.

\section{North-South asymmetry of the biweekly signal}

The energy distribution (Fig. 2 and 3) is not symmetric with respect to the equator. Is it because of a asymmetry in the wind forcing fields? Is it due to the geometry of the coastline in the Gulf of Guinea? Before answering these questions it is important to validate the modelled biweekly signal in the Northern part of the Gulf of Guinea, an analysis made possible by new unpublished data provided by TOTAL. The combination of these new data with the 4-year long time series at the Biozaire site at $7.5^{\circ} \mathrm{S}$ (Vangriesheim et al., 2005; Guiavarc'h et al., 2008) allows us to document the symmetry of the poleward propagating signal, for the first time using direct current measurements. The new mooring was deployed in 1376 m water depth between May 2001 and May 2002 offshore Nigeria. This mooring provides measurements over the whole water column, with two ADCP (RDI 300kHz Workhouse and RDI $75 \mathrm{kHz}$ Long Ranger) located at $100 \mathrm{~m}$ depth and 4 Aanderaa RCM 7/8 current meters at $585 \mathrm{~m}, 879 \mathrm{~m}$, $1190 \mathrm{~m}$ and $1360 \mathrm{~m}$ below sea level.

At all depths, a peak appears in the energy spectra at a period close to 14 days but the peak is not as sharp as in the Biozaire data (not shown). For a direct comparison with the model, a profile of 10-20 day kinetic energy is plotted on Fig. 7. At the Nigeria site (black symbols), the 1020 day signal is maximum in the surface layers, it decreases quickly to $50 \mathrm{~m}$ depth and then slowly to $400 \mathrm{~m}$ where the

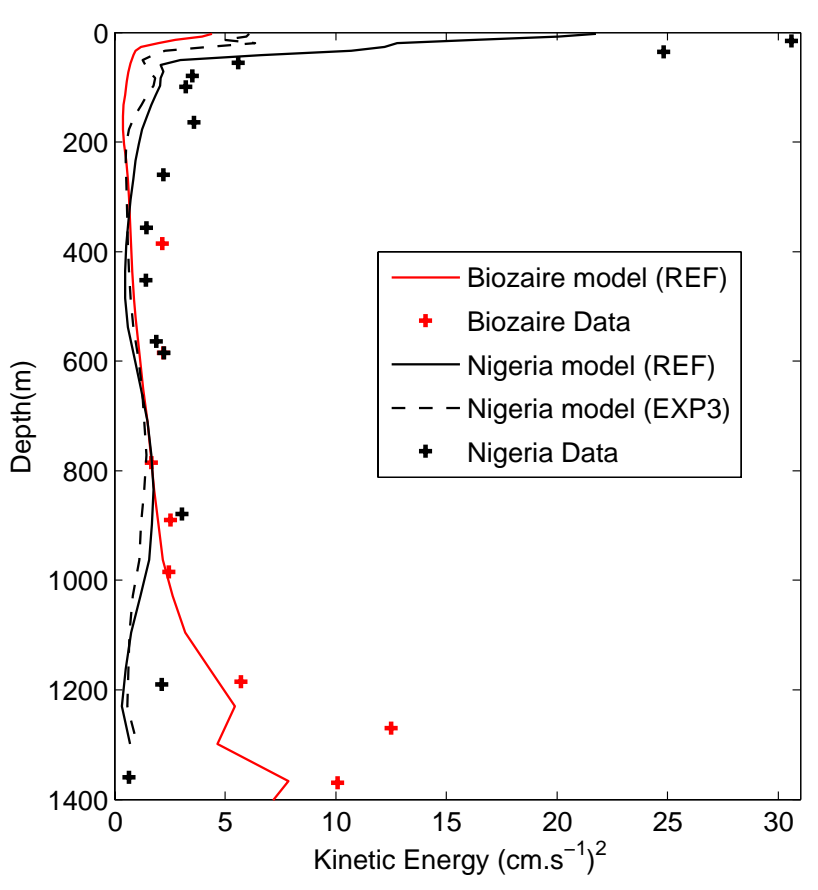

Fig. 7. Kinetic energy in the 10-20 days period band at Nigeria (black) and Biozaire site (red), for the data (symbols) and for the model: REF GUINEA experiment (solid lines), GUINEA model with daily open boundary conditions and monthly winds (EXP3, black dashed line).

signal is minimum. A second energy maximum appears near $800 \mathrm{~m}$ depth. The differences between the Northern site (surface-intensified energy, black symbols) and the southern site (bottom-intensified energy, red symbols) are striking. In the surface layer, the 10-20 day signal is far more energetic in the North (by a factor 5). In contrast, at the deepest level, the southern signal is 3 times more energetic than the northern one. This complex vertical structure is well captured by the model at both sites, as indicated by the continuous lines in Fig. 7. The model allows us to picture the kinetic energy around the two moorings, along sections across the continental slope (Fig. 8). The absence of bottom intensification at the Nigeria site occurs only in a limited depth range; bottom intensification is present in the model over shallower as well as deeper parts of the continental slope. The meridional section at $6^{\circ} 50 \mathrm{E}$ displays the asymmetry of the signal with respect to the equator and the complex vertical structure of the energy around the Sao Tome island on the equator.

One hypothesis to explain the asymmetry is to evoke the asymmetry of the wind-forcing fields. In the eastern tropical Atlantic, the 10-20 day kinetic energy of the QUIKSCAT winds is greater north of the equator than south of the equator for both the zonal and the meridional components (see Fig. 5 in Bunge et al., 2006). To explore the role of the regional winds, we use a sensitivity experiment performed with the GUINEA model. Experiment EXP3 (Guiavarc'h et al., 

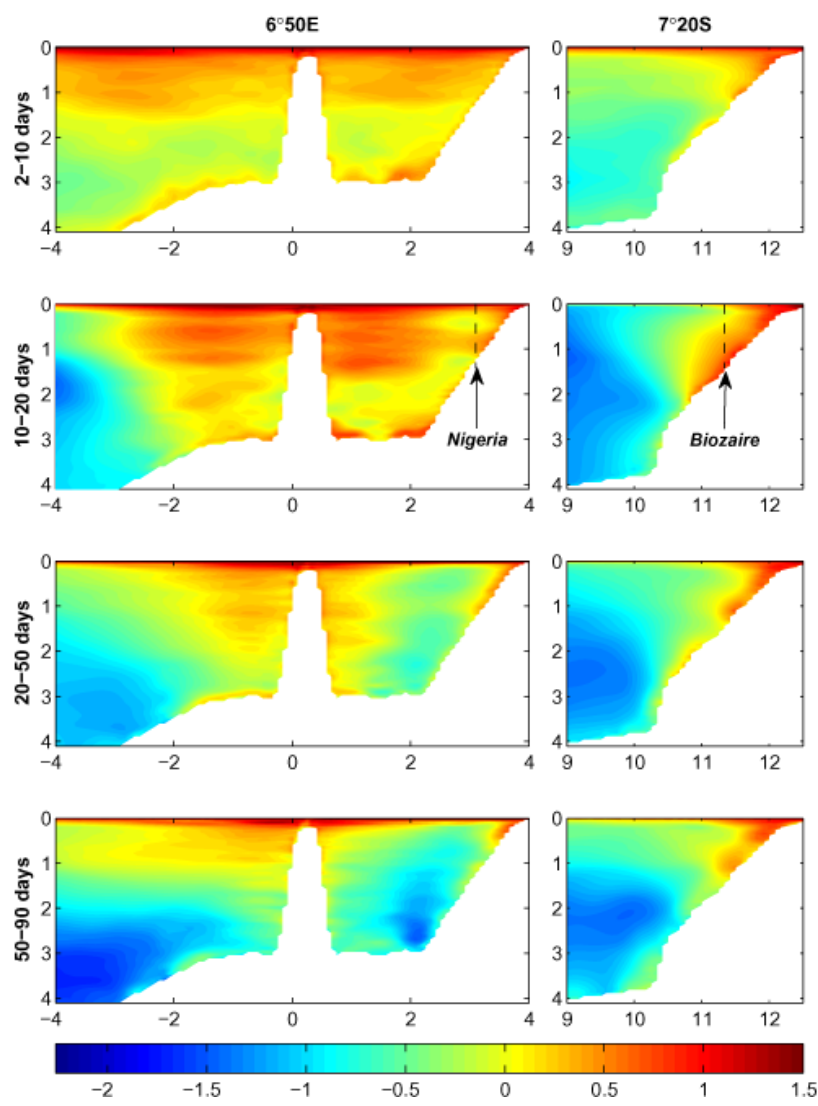

Fig. 8. Sections of kinetic energy in the 10-20 days period band ( $\log 10$ scale): meridional section at $6^{\circ} 50 \mathrm{E}$ and zonal section at $7^{\circ} 20 \mathrm{~S}$ (right). The horizontal scale is latitude (longitude) for the left (right) plot, respectively, in degrees. The vertical scale is depth (in $\mathrm{km}$ ). The position of the Nigeria and Biozaire moorings is indicated.

2008) is forced with daily open boundary conditions but with monthly QUIKSCAT wind fields, instead of the daily winds used for the reference experiment (REF). In EXP3 the signal at 10-20 day periods can propagate into the domain from longitudes west of $2.5^{\circ} \mathrm{W}$, but it cannot be generated by winds over the GUINEA domain. On the Biozaire site, EXP3 displays a 10-20 day kinetic energy profile close to REF (not shown). This led Guiavarc'h et al. (2008) to conclude that the 10-20 day signal is not locally forced at the Biozaire site. On the Nigeria site, the difference between the two experiments is small for the depths below $50 \mathrm{~m}$ (suggesting a remotely forced signal) but on the contrary, the contrast is large near the surface. In the EXP3 experiment with monthly regional winds, the surface signal at the Nigeria site is much weaker, with about the same energy as the surface signal at Biozaire. This demonstrates that the surface intensification of energy at the Nigeria site is due to regional wind forcing over the Gulf of Guinea, which is much more energetic in the 10-20 day period band north of the equator.
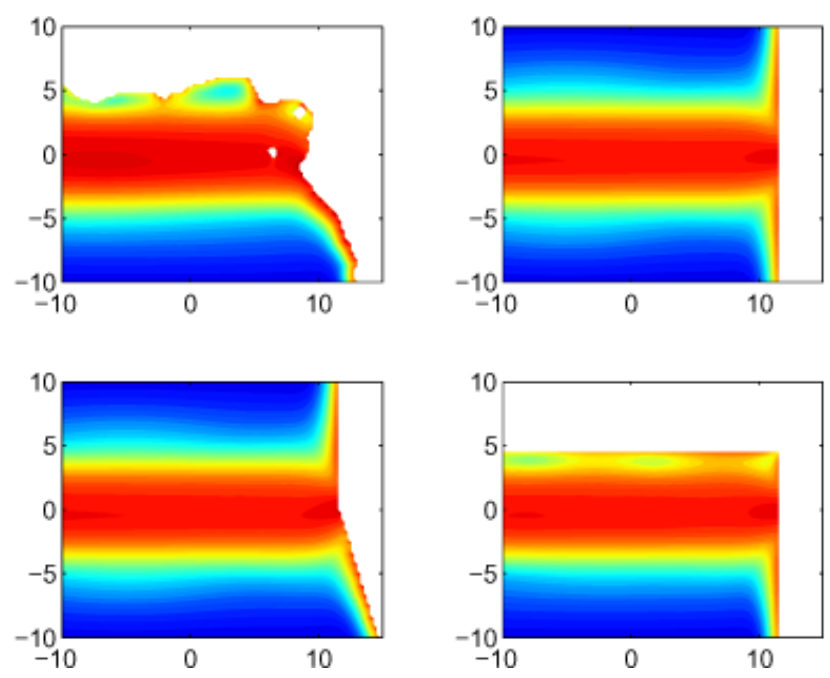

Fig. 9. $\log 10$ of surface kinetic energy in the 10-20 days period in the linear model experiments forced by a 14-day uniform meridional wind stress (horizontal maps as a function of longitude and latitude in degrees). The colorscale is the same for all panels; amplitudes are not significant as they depend upon the arbitrary amplitude of the analytical wind stress.

The model experiments suggests that the 10-20 day oscillations in the deep layers at the Biozaire and Nigeria sites have the same equatorial origin. However, no significant coherence has been found between Biozaire data at $890 \mathrm{~m}$ and Nigeria data for the year 2001 when both dataset are available. At the deepest level, in 2001, the Biozaire data are not available for the whole year (90 days are missing), and we have found marginal coherence with Nigeria. The coherence between the two sites is slightly stronger for the GUINEA model than for the mooring data. The fact that there is no simple phase relationship between the oscillations north and south of the equator may be linked to the complex geometry of the coast.

To explore this hypothesis we haved performed a set of linear model experiments with four different coastlines. We force the linear model with a periodic meridional wind-stress (14-day period), homogeneous over the domain, in order to generate equatorial Yanai waves. The first experiment with realistic coastlines clearly shows that the coastally-trapped signal is stronger south of the equator than north of it (Fig. 9). In the second experiment with a meridional coastline, the coastally-trapped signal is symmetric with respect to the equator. It remains approximately symmetric when the coastline orientation is changed (third experiment) but the asymmetry is recovered when a zonal coastline at $5^{\circ} \mathrm{N}$ is added to schematize the African corner. For the experiment with the idealized zonal coastline at $5^{\circ} \mathrm{N}$, we can see that the energy flux reaching the eastern boundary is modified. A part of the Yanai energy is converted to coastal Kelvin waves propagating westward before reaching the meridional coast. As a 

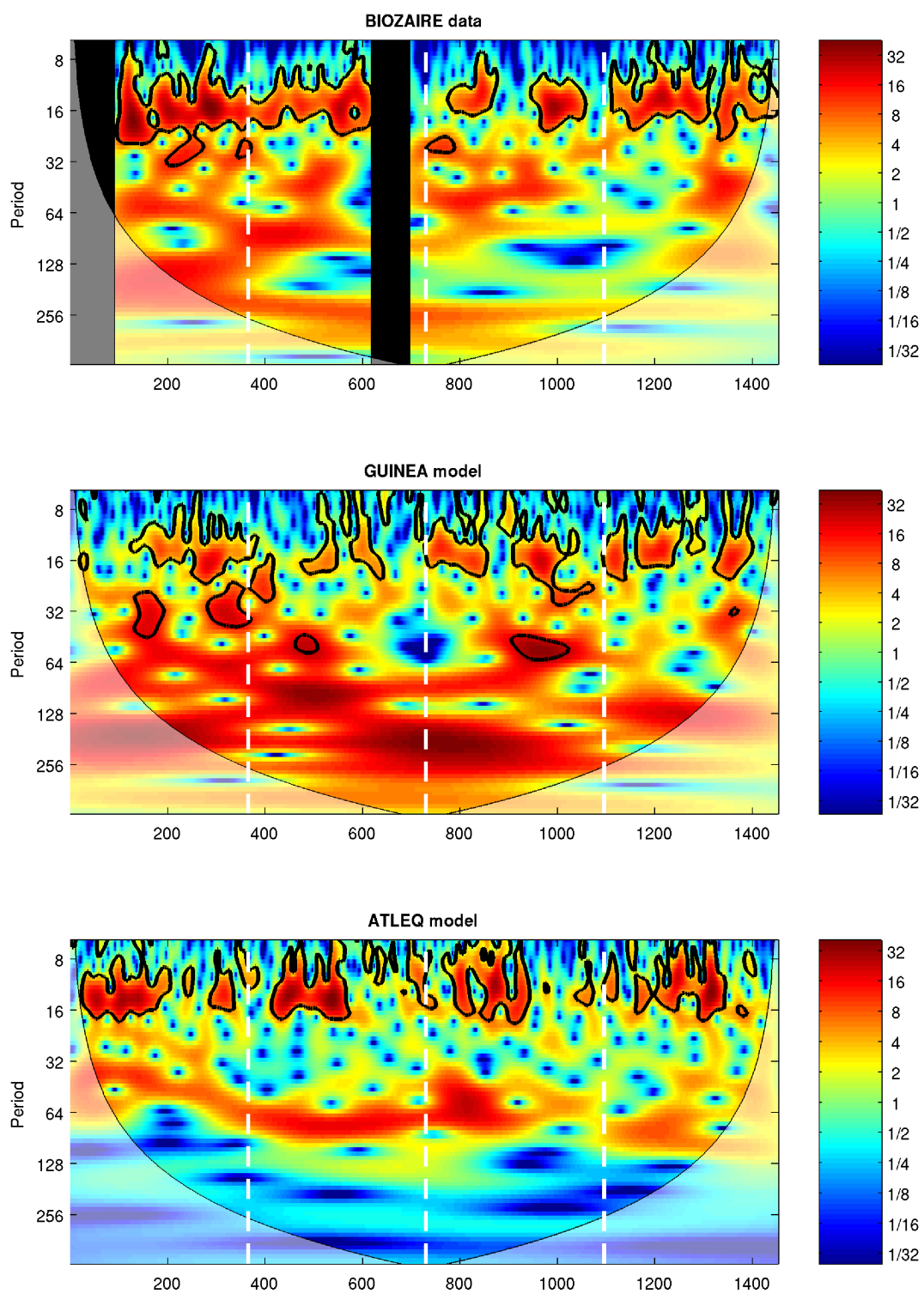

Fig. 10. Wavelet analysis of the alongslope velocity at $1300 \mathrm{~m}$ on Biozaire site for the years 2000-2003. Data are filtered using a Lanczos filter with a cut-off period of 6 days: Biozaire data (top), GUINEA model (middle), linear model (bottom). In the top panel, the two black boxes correspond to the periods when no Biozaire data was available. The time axis in days, and vertical white lines separate the four years (2000 to 2003).

consequence, the flux along the meridional coast between the equator and $5^{\circ} \mathrm{N}$ is less energetic than the flux transmitted to the south. Kaufman et al. (1999) have studied analytically the conversion of the equatorial Yanai waves to coastal waves in the Gulf of Guinea, and demonstrated that a Yanai wave propagating eastward converts a fraction of its energy to a westward propagating coastal Kelvin wave along the zonal African coast near $5^{\circ} \mathrm{N}$. The transmission coefficient $T$, the fraction of Yanai energy flux not converted to the Kelvin wave depends on $L_{c}$ and $\omega$, respectively the wavelength and the frequency of the incident wave:
$T\left(\omega, L_{c}\right)=\exp \left[-(2 \pi)^{\frac{1}{2}}\left(\frac{L_{c}}{y_{N}}\right)\left(\frac{f_{N}}{\omega}\right)^{2} e^{-\frac{\left(\frac{f_{N}}{\omega}\right)^{2}}{2}}\right]$

with $y_{N}$ the distance from the equator to the zonal coast, $f_{N}$ the coriolis parameter at $y_{N}$. Kaufman et al. (1999) find that the conversion is negligible for periods greater than 3 weeks, but substantial for shorter periods, which is consistent with our model results regarding the biweekly waves. 
In summary, our model results show that the asymmetry between the Nigeria and the Biozaire site in the upper layer is due to the regional wind while the asymmetry in the deeper layers is due to the geometry of the African coastlines.

\section{Intermittency}

A strong seasonal cycle is present in the Gulf of Guinea, both in the ocean and in the atmospheric forcing. Does this seasonal cycle have an impact on the generation of intraseasonal waves? Guiavarc'h et al. (2008) showed that on the Biozaire site the 14-day energy varies from year to year but they did not study the variability of the signal for periods less than one year. Polo et al. (2008) used both a simulation of an OGCM and satellite data observations for the 19932000 period to establish a climatology of the intraseasonal (25-95 day) Kelvin waves in the tropical Atlantic. Major activity in the 25-95 day period band occurs during the boreal autumn-winter season. Bunge et al. (2007) showed a 14-day signal due to Yanai waves existing from mid-February until the end of april. Although this Yanai wave are wind-forced, they do not show perfect correspondance with QUIKSCAT wind events and the biweekly oscillations of the current. On the contrary, in the Western Pacific ocean, Zhu et al. (1998) found a direct link between the occurence of a 14-day Yanai wave and a wind event. They found that the 14-day Yanai wave was forced by a northerly wind burst crossing the equator.

Taking advantage of the long time series at the Biozaire site (4 years) we have performed a wavelet analysis on the along-slope currents, which we can compare to the GUINEA model and the linear model (Fig. 10). We use the Matlab toolbox developed by A.Grinsted and available on the website www.pol.ac.uk/home/research/waveletcoherence. For the three time-series, this wavelet analysis confirms the results from the spectral analysis that the 10-20 day signal dominates the other periods most of the time over the 4 years. The 10-20 day signal intermittencies are well-marked in the data and partially reproduced by the GUINEA model, especially the intermittency in 2002. Indeed the biweekly signal disappears twice in the middle and the end of the year 2002 in both the data and the model. However, the GUINEA model does not reproduce the enhanced biweekly signal observed in 2000. The oscillations observed at the Biozaire site propagate from the equator, but we do not find correlations between the biweekly current oscillations on Biozaire and the equatorial wind events. This is expected since even at the equator such correlations are difficult to establish (Bunge et al., 2007).

No clear seasonal cycle of the biweekly oscillations appears in the observations nor the GUINEA model, but there is a seasonal cycle in the linear model (Fig. 10), with stronger energy during boreal winter and spring. This strong seasonal cycle reflects the seasonal cycle of the equatorial winds.
However, even in the linear model there is no well defined correlation between oscillations at the Biozaire site and equatorial wind oscillations at a particular location. This happens because the Yanai waves responsible for the oscillations at Biozaire are forced all along the equatorial waveguide: the coastal waves result from the sum of all the Yanai waves forced at different longitudes. The lag between an equatorial wind event and the arrival of the biweekly waves at the Biozaire site depend on the longitude at which the wind events occur. Unlike the spatial structure of the intraseasonal signal, which can be explained to a large extend by linear theory, we find that the intermittency of the biweekly signal is not a linear response to wind events. The GUINEA model reproduces this intermittency but only qualitatively.

\section{Conclusions}

In this paper we have used numerical models to map for the first time the intraseasonal variability of deep currents in the Gulf of Guinea. Our focus was initially the currents along the continental slope, where our observations are available. However we have considered the full three dimensional structure of intraseasonal energy, in the interior as well as along the coast. The high resolution of the GUINEA model, $1 / 12^{\circ}$ and 100 vertical layers, has been shown to be essential to reproduce the bottom intensification of energy on the continental slope at the Biozaire site (Guiavarc'h et al., 2008). Here we find that the model is also in remarkable agreement with observations at another location off Nigeria, north of the equator. This location is characterized by a completely different energy profile in the 10-20 day period band (a surfaceintensified energy with a second deep maximum, and no bottom intensification). The model reproduces the energy profile and explains its characteristics: the surface intensification is due to regional wind forcing, and the complex vertical structure at depth is related to the shape of the African coastline.

The success of the model at reproducing the observed current profiles at two locations gives us confidence that our energy maps bear some resemblance with the real ocean. The fact that the complex three-dimensional structure of energy is (at first order) reproduced by a linear shallow water model is also encouraging. This suggests that the energy maps can be interpreted in terms of equatorial waves and coastal Kelvin waves. Our study, like Guiavarc'h et al. (2008), emphasizes the equatorial origin of the energy along the continental slope. Even in the linear model, the structure of the kinetic energy at depth is complex: it is asymmetric with respect to the equator due to the shape of the African coastline. Moreover, in the GUINEA model the energy distribution appears to be influenced by bottom topography (the continental slope and islands such as Sao Tome), making it even more complicated. On the horizontal, the model shows intensification of energy on convex portions of the coasline. 
In the vertical, there are localized bottom intensifications. The three-dimensional structure depends on the frequency considered. For example, the 10-20 day period band display the largest coastal intensification, due to the absence of westward propagating waves along the equator in that period band; long periods (50-90 days) have the most complex vertical structure at the equator.

We must acknowledge that the spatial resolution of the GUINEA model is still inadequate in some regions of the continental slope. A clear demonstration has been provided by recent current measurements carried out as part of the Biozaire program, at the exit of the Congo channel (REGAB site, Vangriesheim et al., 2009). The REGAB mooring at $3170 \mathrm{~m}$ depth at the mouth of the Congo channel exhibits energetic biweekly oscillations polarized in the east-west direction, probably because of the direct influence of the canyon cutting across the continental slope. The deep-sea channel width (less than $2 \mathrm{~km}$ at the REGAB site) is not resolved by the GUINEA model grid, which fails to reproduce the polarization and intensity of the observed current oscillations at that location.

Regarding larger scales (resolved by the model), the dynamics and the spatial structure of intraseasonal waves in the Gulf of Guinea appear mainly linear, but despite this fact the intermittency of the 14-day signal observed at the Biozaire site is not a linear response to wind events. While the 14-day winds display a strong seasonal cycle along the equator, the deep biweekly oscillations at Biozaire do no have a similar cycle and the periods with strong (or weak) biweekly signals on Biozaire are not correlated with high- (or low-) energetic 14-day wind fluctuations. The GUINEA model reproduces partially the intermittency of the 14-day signal. In contrast, the 14-day signal in the linear model has a well-marked seasonal cycle due to the seasonal variability of the wind fields.

Thus, the GUINEA model can be considered very successful in a qualitative sense, but it fails to reproduce observed events such as the intensification of the 14-day current oscillations at the Biozaire site during 2000. We do not know yet whether this event was deterministic, and could be reproduced with a more accurate model and/or atmospheric forcing, or if such events are due to a nonlinear variability of the ocean that cannot be simulated without introducing a constraint to in-situ observations. In the latter case, the variability of currents along the slope of the Gulf of Guinea will be difficult to forecast, because data assimilation techniques are not yet reliable in the vicinity of strong topographic slopes.

\section{Appendix A}

\section{Description of the GUINEA model}

A description of the regional model (GUINEA) is found in Guiavarc'h et al. (2008) and is repeated here for completeness. The model is based on the primitive equation code NEMO/OPA.9 developed at LOCEAN (http://www. locean-ipsl.upmc.fr/NEMO), in its version 1.06. It is a second order finite difference model with a free surface, formulated in z-coordinates. We use the partial step representation of the bathymetry and the new momentum advection scheme discussed by Barnier et al. (2006). The horizontal grid is a Mercator grid with a resolution $1 / 12^{\circ}$, covering the Gulf of Guinea from $15^{\circ} \mathrm{S}$ to the Northern African coast near $5^{\circ} \mathrm{N}$ and from $2.5^{\circ} \mathrm{W}$ to the eastern African coast. The vertical grid has 100 levels with $5 \mathrm{~m}$ resolution at the surface and $70 \mathrm{~m}$ resolution below $1500 \mathrm{~m}$. This vertical resolution allows the strong stratification in the surface layers of the the Gulf of Guinea to be resolved as well as the currents near the bottom. The model bathymetry is based on ETOPO2 (Smith and Sandwell, 1997) smoothed by twice applying a Shapiro filter. The vertical mixing is performed by a second order (TKE) closure scheme. Bottom friction is nonlinear, with drag coefficient $C d=1 \cdot 10^{-3}$. A horizontal biharmonic operator is used for the lateral mixing of both tracers and momentum with a coefficient equal to $5.10^{9} \mathrm{~m}^{4} \mathrm{~s}^{-1}$. A Laplacian operator with a coefficient equal to $350 \mathrm{~m}^{2} \mathrm{~s}^{-1}$ has been added at the equator (between $3^{\circ} \mathrm{S}$ and $3^{\circ} \mathrm{N}$ ) in the upper $500 \mathrm{~m}$ following Arhan et al. (2006). This additional mixing in the upper equatorial band was needed to control the strength of the equatorial undercurrent.

Open boundary conditions have been applied at the West and South boundaries following the method described in Treguier et al. (2001), with an additional Laplacian operator for momentum in "sponge layers" along the two boundaries. At the boundaries we need data for temperature, salinity and the velocity component normal to the boundary, at high frequency (daily). We use a lower resolution model $\left(1 / 4^{\circ}\right)$ in a larger domain including the GUINEA model region, and forced with the same atmospheric data. This model, called NATL, is similar to the one described in Le Sommer et al. (2009), except for a reduced northward extension and the absence of an ice model. It covers the Atlantic ocean from $24^{\circ} \mathrm{S}$ to $70^{\circ} \mathrm{N}$ with a $1 / 4^{\circ}$ horizontal resolution and 46 vertical levels.

Both GUINEA and NATL are initialized using the Levitus climatology. The models are spun up for 5 years (1995-1999) using the forcing dataset of Large and Yeager (2004). This dataset has been designed for CORE (Coordinated Ocean Reference Experiments, Griffies et al., 2009), and includes carefully balanced data from various origins. The daily radiative fluxes and monthly precipitation are from satellite observations. The 6-hourly temperature, specific humidity and $10 \mathrm{~m}$ winds come from the NCEP/NCAR reanalysis. The turbulent fluxes are calculated using the CORE bulk formulae. We use the monthly climatology of river runoffs of Dai and Trenberth (2002). To avoid a large model drift due to the uncertainties in the freshwater fluxes, there is a relaxation of sea surface salinity to the LEVITUS climatology with a coefficient of $0.25 \mathrm{~m} \mathrm{day}^{-1}$. The reference experiment (REF) is run for the years 2000 to 2004 following the 
Table B1. Phase velocities $\left(c_{n}\right)$ and decay times for the six baroclinic modes used in the linear model.

\begin{tabular}{lcc}
\hline Mode & $c_{n}\left(\mathrm{~m} \mathrm{~s}^{-1}\right)$ & Decay time (day) \\
\hline 1 & 2.35 & 839 \\
2 & 1.35 & 316 \\
3 & 0.92 & 156 \\
4 & 0.71 & 81 \\
5 & 0.54 & 55 \\
6 & 0.46 & 50 \\
\hline
\end{tabular}

spin up, with CORE forcing excepted for the wind speed (we use daily winds from the QUIKSCAT satellite diffusiometer, Bentamy et al., 2002).

\section{Appendix B}

\section{Description of the linear model}

The linear shallow water model has been constructed by a simplification of the NEMO-OPA9 code, keeping the horizontal "C" grid and finite difference algorithms. For each vertical mode $n$, the following equations are solved:

$$
\begin{gathered}
\frac{\partial u_{n}}{\partial t}-f v_{n}=\frac{\tau_{x}}{h_{\operatorname{mix}} \rho_{0}}-g \frac{\partial \eta_{n}}{\partial x}-\frac{u_{n}}{r_{n}}+v \nabla^{4} u_{n} \\
\frac{\partial v_{n}}{\partial t}+f u_{n}=\frac{\tau_{y}}{h_{\operatorname{mix}} \rho_{0}}-g \frac{\partial \eta_{n}}{\partial y}-\frac{u_{n}}{r_{n}}+v \nabla^{4} v_{n} \\
\frac{\partial \eta_{n}}{\partial t}=-\frac{c_{n}^{2}}{g}\left(\frac{\partial u_{n}}{\partial x}+\frac{\partial v_{n}}{\partial y}\right)-\frac{\eta_{n}}{r_{n}}
\end{gathered}
$$

where $u_{n}(x, y, t)$ and $v_{n}(x, y, t)$ are the velocities for mode $n, \eta_{n}$ is the equivalent height, $f=\beta y$ is the Coriolis parameter for an equatorial $\beta$-plane, $c_{n}$ is the phase speed of mode $n$ and $g$ the acceleration of gravity. The wind stress $\tau_{x}, \tau_{y}$ is supposed to act over a depth $h_{\text {mix }}$ which is set to $50 \mathrm{~m}$. Dissipation occurs by biharmonic viscosity with coefficient $\nu=510^{12} \mathrm{~m}^{4} \mathrm{~s}^{-1}$ and a Rayleigh damping with time scale $r_{n}$.

The vertical mode decomposition requires neglecting bottom topography: a uniform depth of $4000 \mathrm{~m}$ is assumed. The structure functions $F_{n}(z)$ of the vertical modes as well as the phase velocities are calculated using a climatological profile of stratification averaged over the equatorial Atlantic between $5^{\circ} \mathrm{S}$ and $5^{\circ} \mathrm{N}$ (Guiavarc'h, 2007). The decay time is assumed to decrease with mode number in the following manner after Gent et al. (1983):

$r_{n}=r_{1}\left(\frac{c_{n}}{c_{1}}\right)^{q}$

with $q=1.675$. Illig et al. (2004) have tested different decay times and they have found that this formulation gave the best fit between a linear model and a primitive equation model in the equatorial Atlantic. The phase speeds and decay times are indicated in Table B1.

The model domain extends from $60^{\circ} \mathrm{W}$ to $17.7^{\circ} \mathrm{E}$ and from $30^{\circ} \mathrm{S}$ to $30^{\circ} \mathrm{N}$ with the same $1 / 4^{\circ}$ grid and coastline as the NATL model. We use quickscat wind stress forcing for the years 2000-2004 with the time average removed, to avoid a long spin-up at mid-latitudes. The model is run once for the year 2000 to spin-up the seasonal cycle, and then again for 2000-2004. The velocity fields at any given depth can be reconstructed using the modal velocities $u_{n}, v_{n}$ and the vertical mode structure functions $F_{n}(z)$.

Acknowledgements. We thank TOTAL for providing mooring data to complement the data of the Biozaire project of IFREMER (also partially funded by TOTAL). Computations presented in this study have been run on the parallel computer at the CNRS Institut du Developpement et des Ressources en Informatique Scientifique (IDRIS), Orsay, France. The thesis of C. Guiavarc'h has been funded jointly by IFREMER and TOTAL. Annick Vangriesheim is supported by IFREMER and Anne Marie Treguier by CNRS.

Edited by: M. Hecht

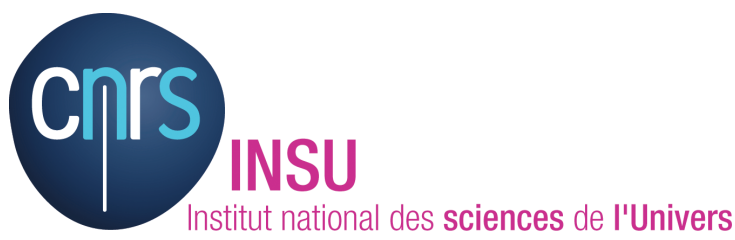

The publication of this article is financed by CNRS-INSU.

\section{References}

Arhan, M., Treguier, A. M., Bourles, B., and Michel, S.: Diagnosing the annual cycle of the Equatorial Undercurrent in the Atlantic Ocean from a General Circulation Ocean Model, J. Phys. Oceanogr., 36, 1502-1522, 2006.

Barnier, B., Madec, G., Penduff, T., Molines, J. M., Treguier, A. M., Le Sommer, J., Beckmann, A., Biastoch, A., Böning, C., Dengg, J., Derval, C., Durand, E., Gulev, S., Remy, E., Talandier, C., Theetten, S., Maltrud, M., McClean, J., and De Cuevas, B.: Impact of partial steps and momentum advection schemes in a global ocean circulation model at eddypermitting resolution, Ocean Dynamics, 56, 543-567, doi:10. 1007/s10236-006-0082-1, 2006.

Bentamy, A., Quilfen, Y., and Flament, P.: Scatterometer wind fields : A new release over the decade 1991-2001, Can. J. Remote Sens., 28, 431-449, 2002.

Brink, K. H. and Chapman, D. C.: Program for computing properties of coastal-trapped waves and wind-driven motions over the continental shelf and slope, Second ed., Woods Hole Oceanographic Institution Technical Reports, WHOI-87-24, 119 pp., 1987.

Bunge, L., Provost, C., Lilly, J., D’Orgeville, M., Kartavtseff, A., and Melice, J. L.: Variability of the Horizontal Velocity Structure in the Upper $1600 \mathrm{~m}$ of the water Column on the Equator at $10^{\circ} \mathrm{W}, \mathrm{J}$. Phys. Oceanogr., 36, 1287-1304, 2006. 
Bunge, L., Provost, C., and Kartavtseff, A.: Variability in horizontal current velocities in the central and eastern equatorial Atlantic in 2002, J. Geophys. Res., 112, C02014, doi: 10.1029-2006JC003704, 2007.

Clarke, A. J.: Reflexion of Equatorial Waves from Oceanic Boundaries, J. Phys. Oceanogr., 13, 1193-1207, 1983.

Clarke, A. J. and Battisti, D. S.: Identification of the fortnightly wave observed along the Northern Coast of the Gulf of Guinea, J. Phys. Oceanogr., 13, 2192-2200, 1983.

Dai, A. and Trenberth, K. E.: Estimates of freshwater discharge from continents: latitudinal and seasonal variations, J. Hydrometeorol., 3, 660-687, 2002.

Enfield, D., del Pilar Corneijo-Rodrigez, M., Smith, R., and Newberger, P.: The equatorial source of propagating variability along the Peru coast during the 1982-1983 El Nino, J. Geophys. Res., 92(C13), 14335-14346, 1987.

Gent, P. R., O'neill, K., and Cane, M. A.: A Model of the Semiannual Oscillation in the Equatorial Indian Ocean, J. Phys. Oceanogr., 13, 2148-2160, 1983.

Griffies, S. M., Biastoch, A., Boning, C., Bryan, F., Danabasoglu, G., Chassignet, E. P., England, M. H., Gerdes, R., Haak, H., Hallberg, R. W., Hazeleger, W., Jungclaus, J., Large, W. G., Madec, G., Pirani, A., Samuels, B. L., Scheinert, M., Gupta, A. S., Severijns, C. A., Simmons, H. L., Treguier, A. M., Winton, M., Yeager, S., and Yin, J.: Coordinated Ocean-Ice reference experiments (COREs), Ocean Modell., 26, 1-46, 2009.

Guiavarc'h, C.: Modelisation haute-resolution des courants dans le Golfe de Guinée: Etude des oscillations bimensuelles, Ph.D. thesis, Universite de Bretagne Occidentale, France, 2007.

Guiavarc'h, C., Treguier, A., and Vangriesheim, A.: Remotely forced biweekly deep oscillations on the continental slope of the Gulf of Guinea, J. Geophys. Res., 113, C06002, doi:10.1029/ 2007JC004471, 2008.

Han, W., Webster, P. J., Lin, J. L., Liu, W. T., Fu, R., Yuan, D., and $\mathrm{Hu}, \mathrm{A} .:$ Dynamics of intraseasonal sea level and thermocline variability in the equatorial Atlantic during 2002-2003, J. Phys. Oceanogr., 38, 945-967, 2008.

Houghton, R. W.: Characteristics of the Fortnightly Shelf Wave Along the Ghana Coast, J. Geophys. Res., 84(C10), 1077710786, 1979.

Houghton, R. W. and Beer, T.: Wave propagation during the Ghana upwelling, J. Geophys. Res., 81, 4423-4429, 1976.

Hua, B. L., D’ORgeville, M., Fruman, M. D., Menesguen, C., Schopp, R., Klein, P., and Sasaki, H.: Destabilization of mixed Rossby gravity waves and the formation of equatorial zonal jets, Journal of Fluid Mechanics, 610, 311-341, doi:10.1017/ S0022112008002656, 2008.

Huthnance, J. M.: On coastal trapped waves: analysis and numerical calculation by inverse iteration, J. Phys. Oceanogr., 8, 73-94, 1978.

Illig, S., Dewitte, B., Ayoub, N., du Penhoat, Y., Reverdin, G., De Mey, P., Bonjean, F., and Lagerloef, G.: Interannual long equatorial waves in the tropical Atlantic from a high resolution ocean general circulation model experiment in 1981-2000, J. Geophys. Res., 109, C02022, doi:10.1029/2003JC001771, 2004.

Kaufman, A. N., Morehead, J. J., Brizard, A. J., and Tracy, E. R.: Mode conversion in the Gulf of Guinea, J. Fluid Mech., 394, 175-192, 1999.
Large, W. and Yeager, S.: Diurnal to decadal global forcing for ocean sea-ice models: the data sets and flux climatologies, NCAR Technical Note: NCAR/TN-460+STR, CGD Division of the National Center of Atmospheric Research, 2004.

Le Sommer, J., Penduff, T., Theetten, S., Madec, G., and Barnier, B.: How momentum advection shemes influence current topography interactions at eddy permitting resolution, Ocean Modell., 29, 1-14, doi:10.1016/j.ocemod.2008.11.007, 2009.

Madec, G.: NEMO ocean engine, Note du Pole de modlisation, Institut Pierre-Simon Laplace (IPSL), France, No. 27 ISSN, 12881619, 2008.

Miyama, T., McCreary, J. P., Sengupta, D., and Senan, R.: Dynamics of Biweekly Oscillations in the Equatorial Indian Ocean, J. Phys. Oceanogr., 36, 827-846, 2006.

Philander, S. G. H.: The effects of coastal geometry on equatorial waves (Forced waves in the Gulf of Guinea, J. Mar. Res., 35, 509-523, 1977.

Picaut, J. and Verstraete, J. M.: Propagation of a 14.7 day wave along the northern coast of the Gulf of Guinea, J. Phys. Oceanogr., 9, 136-149, 1979.

Polo, I., Lazar, A., B, R.-F., and Arnault, S.: Oceanic Kelvin Waves and Tropical Atlantic intraseasonal Variability. Part I: Kelvin wave characterization, J. Geophys. Res., 113, C07009, doi:10.1029/2007JC004495, 2008.

Sengupta, D., Senan, R., Murty, V. S. N., and Fernando, V.: A beweekly mode in the equatorial Indian Ocean, J. Geophys. Res., 109, C10003, doi:10.1029/2004JC002329, 2004.

Shaffer, G., Pizarro, O., Djurfeldt, L., Salinas, S., and Rutllant, J.: Circulation and low-frequency variability near the Chilean coast: Remotely forced fluctuations during the 1991-1993 El Nino, J. Phys. Oceanogr., 27, 217-235, 1997.

Smith, W. H. F. and Sandwell, D. T.: Global seafloor topography from satellite altimetry and ship depth sounding, Science, 277, 1957-1962, 1997.

Soares, J., Wainer, I., and Wells, N. C.: Reflection of equatorial Kelvin waves at eastern ocean boundaries Part II: Pacific and Atlantic Oceans, Ann. Geophys., 17, 827-837, 1999, http://www.ann-geophys.net/17/827/1999/.

Thierry, V., Mercier, H., and Treguier, A.: Seasonal fluctuations in the deep central equatorial Atlantic Ocean: a datamodel comparison, Ocean Dynamics, 56, 581-593, doi:10.1007/ s10236-005-0045-y, 2006.

Treguier, A. M., Barnier, B., de Miranda, A., Grima, N., Imbard, M., Le Provost, C., Madec, G., Messager, C., Molines, J. M., Michel, S., and Reynaud, T.: An eddy permitting model of the Atlantic circulation: evaluating open boundary conditions, J. Geophys. Res., 106, 22115-22129, 2001.

Vangriesheim, A., Treguier, A., and Andre, G.: Biweekly current oscillations on the continental slope of the Gulf of Guinea, Deep Sea Res. I, 52, 2168-2183, 2005.

Vangriesheim, A., Khripounoff, A., and Crassous, P.: Turbiditic events observed in situ along the Congo seep-sea channel, Deep sea Res., doi:10.1016/j.dsr2.2009.04.004, in press, 2009.

Zhu, X. H., Kaneko, A., Gohda, N., Inaba, H., Kutsuwada, K., and Radenac, M. H.: Observation of Mixed Rossby-Gravity Waves in the Western Equatorial Pacific, J. Oceanogr., 54, 133-41, 1998. 